\title{
PSYCHE.
}

\section{A PRELIMINARY CLASSIFICATION OF THE TRYXALINAE OF THE UNITED STATES AND CANADA.}

BY SAMUEL H. SCUDDER, CAMBRIDGE, MASS.

The Tryxalinae of this country were first made known in tolerable completeness and systematic shape by McNeill in an important paper published a little more than a year ago. His table for the separation and sequence of the genera was, with slight changes (mainly to admit a few types which were rejected by him and to omit one belonging elsewhere) copied by me in my recent Guide to North American Orthoptera, because this latter work was published immediately after the issue of McNeill's Revision; was in fact awaiting its issue. But I there expressed the opinion that the order and alliance of the genera, especially with the changes I had introduced, left much to be desired, and I therefore prepared the subjoined table, which seems to me to place the genera in better order and indicates at the same time some of the larger groups. This arrangement is also in better harmony with the general outline of the classification of the Tryxalinae of the world given by Brunner von Wattenwyl in his Système in 1893 , which was too little regarded by McNeill. Some of the new genera indicated by Brunner at that time and unrecognized by McNeill are here included.

The table has been subjected to some use and found to answer tolerably well, though I am not entirely satisfied with it and therefore publish it only as a preliminary attempt, which I hope to improve with time and criticism. It was intended to be accompanied by the addition of descriptions of a number of new forms, but as this part must be deferred under the pressure of other demands, I shall hope to reissue the table in a revised form when the descriptive portion is ready. Meanwhile, in explanation of certain points, I add a few notes referred to by number in the table and given at the close. They relate principally to the new names here introduced and to the synonymy of some of the genera. Except to indicate the types of the new genera, no reference to species is made in this paper.

It is well to remark that our Tryxaline fauna is composed almost entirely of endemic types, only three of its thirtyseven genera being common to the Old World and the New, and these three being boreal types. 


\section{TABLE OF THE GENERA OF TR YXALINAE.}

$A^{1}$. Foveolae of the vertex wanting or invisible from above, their plane forming a right or acute angle with the plane of the fastigium; face usually more oblique than in the alternate category.

$b^{1}$. Sides of the fastigium strongly rounded so that the apex is in no way acuminate; antennae depressed ensiform; tegmina acuminate or angulate at apex; genicular lobes of hind femora (and generally also the genicular angle itself) horizontally produced and acuminate (Hyalopteriges).

$c^{1}$. Fastigium greatly produced, as long as or longer than the eye, its sides on basal half subparallel; face excessively oblique, the eyes sublongitudinal; genicular angle of hind femora longitudinally produced and acuminate.

$d^{1}$. No foveolae of the vertex; tegmina very much shorter than the abdomen; spines of outer margin of hind tibiae numerous, about 25 in number; subgenital plate of male abdomen excessively elongate. . . . . . Rhadinotatum McNeill (Note I). $d^{2}$. Foveolae of vertex narrow, elongate; tegmina surpassing the abdomen; spines of outer margin of hind tibiae less numerous, about $\mathbf{r} 6$ in number; subgenital plate of male abdomen of moderate length.

Achurum Saussure.

$c^{2}$. Fastigium subtriangular, not greatly produced, distinctly shorter than the eyes, the sides converging from the base; face less oblique, the eyes distinctly oblique; genicular angle of hind femora not longitudinally produced, but roundly deflexed, blunt. . Tryxalis Fabricius (Note 2). $b^{2}$. Sides of the fastigium straight or gently rounded, so that the fastigium is more or less acuminate; antennae variable; tegmina apically rounded ; genicular lobes of hind femora apically rounded, the genicular angle roundly deflexed, blunt.

$c^{1}$. Hind tibiae armed with numerous spines, numbering $15^{-20}$, usually 18-20, on the outer margin (Mermiriae).

$d^{1}$. Antennae long, ensiform; eyes of $q$ somewhat shorter than the infraocular portion of the genae; prosternum with a distinct tubercle; anterior ulnar vein of tegmina situated midway between the radial and posterior ulnar veins, the lower area reticulate in both sexes.

Mermiria Stål. $d^{2}$. Antennae filiform, apically ampliate in the $\delta$; eyes longer than the infraocular portion of the genae in both sexes; prosternum with no tubercle; anterior ulnar vein of tegmina nearer the radial than 
the posterior ulnar, this lower field regularly fenestrate in the $\delta$, densely reticulate in the.$+ \quad$. . . . . Syrbula Stal. $c^{2}$. Hind tibiae armed with less numerous spines, rarely numbering as many as 15 , usually only ro-r 2 , on outer margin.

$d^{1}$. Radial veins in apical third of wing in $\delta$ normal, not constricted nor specially incrassate, the discoidal field not fenestrate.

$e^{1}$. Head usually more or less conical, ascending, sometimes strongly; eyes usually prominent; upper portion of frontal costa produced so that the front, as seen laterally, is more or less sinuate or excavato-angulate at the ocellus; wings usually banded or highly colored (Acrolophiti).

$f^{1}$. Head as viewed laterally strongly ascending; face below ocellus subperpendicular; antennae more than half as long as the tegmina; metazona distinctly elevated above the prozona, tumid or crested.

$g^{1}$. Metazona much longer than prozona, with an elevated but tumid crest. Acrolophitus Thomas.

$g^{2}$. Metazona barely longer than prozona, tumid, but with only a slight carina. Acrocara Scudder.

$f^{2}$. Head as viewed laterally with scarcely ascending vertex; face below ocellus distinctly though not greatly oblique ; antennae less than half as long as tegmina; metazona not or barely elevated above the prozona, feebly tumid at most.

$g^{1}$. Antennae much longer than the face; lower margin of lateral lobes anteriorly excised, broadly exposing the pleura; basal third of tegmina densely reticulate, the intercalary vein obscure.

Pedioscirtetes Thomas.

$g^{2}$. Antennae shorter than the face; lower margin of lateral lobes nearly horizontal throughout, scarcely exposing the pleura; only the extreme base of the tegmina densely reticulate, the intercalary vein distinct. . . . . . Gymnes Scudder. $e^{2}$. Head obscurely or not conical, never, unless very feebly, ascending; eyes seldom prominent; face, as seen laterally, straight throughout or uniformly rounded, never sinuate or excavato-angulate; wings generally clear or (apically) faintly fuliginous. 
$f^{1}$. Head somewhat ascending; antennae of very unequal length in the two sexes; pronotum with no lateral carinae, the median carinae obsolete on the prozona; scapular area of $\delta$ tegmina conspicuously expanded, so as to make the costal margin sinuate (Bootettiges). Bootettix Bruner. $f^{2}$. Head generally salient, rarely at all ascending; antennae subequal in the two sexes; scapular area of male tegmina not or but little, rarely at all conspicuously, expanded, never considerably disturbing the regular curve of the costal margin.

$g^{1}$. Antennae distinctly flattened (except in Amblytropidia), rather short*; fastigium usually rotundate without distinct lateral costulation or, if distinct, then with a distinct median carina, generally continuing over the occiput, sometimes there accompanied by a pair of submedian carinae; face strongly or rather strongly oblique; lateral carinae of pronotum usually parallel but sometimes converging mesially but without any, or but the faintest, constriction of the body of the pronotum (Amblytropidiae).

$h^{1}$. Disk of pronotum more or less clepsydral, the lateral carinae converging near the middle so as to be there nearer together than at either the front or hind margin.

$i^{1}$. Apical spurs on inner side of hind tibiae very unequal in length.

$j^{1}$. Antennae apically clavate; lateral carinae of pronotum subparallel; tegmina as long as abdomen.

Eritettix Bruner.

$j{ }^{2}$. Antennae apically attenuate though blunt; lateral carinae of pronotum considerable arcuate; tegmina abbreviate. $k^{1}$. Hind margin of pronotum angulate or rotundato-angulate; prozona but little longer than metazona.

Mesochloa n. g. (Note 3). 
$k^{2}$. Hind margin of pronotum truncate; prozona much longer than metazona.

Macneillia n. n. (Note 4). $i^{2}$. Apical spurs on inner side of hind tibiae subequal. Acentetus McNeill. $h^{2}$. Disk of pronotum equal or subequal, the lateral carinae being strictly parallel or diverging only (and slightly) on the metazona.

$i$. Scapular area of tegmina in both sexes dilated, subhyaline, regularly areolate with oblique veinlets.

$j^{1}$. Antennae feebly clavate in $\delta^{\pi}$, depressed but not basally expanded in $q$; supplementary subdorsal carinae on pronotum. . Amphitornus McNeill. $j^{2}$. Antennae apically acuminate in $\delta$, basally expanded so as to be subensiform in $\$$; no supplementary carinae on pronotum. Opeia McNeill (Note 5). $i^{2}$. Scapular area of tegmina in both sexes not at all dilated, of the same density as the other areas. . Amblytropidia Stål. $g^{2}$. Antennae but little or not flattened, filiform, generally long; fastigium more or less excavate or, if rotundate, with distinct lateral costulation; no median carina on head unless the fastigium is deeply sunken, with high margins; no supplementary carinae; face usually subvertical; lateral carinae of pronotum strongly converging mesially, the pronotum being mesially constricted (Phlibostromae).

$h^{1}$. Face strongly oblique; eyes oblique; scapular area of tegmina in both sexes broader apically than basally; prozona much longer than metazona, the latter subtruncate posteriorly.

Alpha Brunner.

$h^{2}$. Face subperpendicular; eyes subvertical; scapular area of tegmina in both sexes broader basally than apically; prozona and metazona of subequal length, the latter angulate posteriorly. 
$i^{1}$. Antennae much longer than head and pronotum together; no median carina on head, except sometimes posteriorly; interspace between eyes as broad as the narrowest part of pronotal disk; longest hind tibial spur scarcely longer than last tarsal joint.

Phlibostroma Scudder (Note 6). $i^{2}$. Antennae no longer than head and pronotum together; a percurrent median carina on head; interspace between eyes hardly if any more than half as broad as narrowest part of pronotal disk; longest hind tibial spur distinctly longer than last tarsal joint.

Psoloessa Scudder.

$d^{2}$. Radial veins in apical third of wings of $\delta$ incrassate and constricted, the discoidal field fenestrate (Orphulae).

$e^{1}$. Antennae relatively short, at most but little longer than head and pronotum together; fastigium of vertex with no median carina; scapular area of tegmina not specially dilated.

$f^{1}$. Foveolae of vertex more or less evident; prozona not much longer than metazona; lateral lobes of pronotum transverse, i.e., deeper than long; upper ulnar vein of tegmina, at least in $\delta$, apically joining the lower ulnar vein at a long distance beyond the end of the basodiscoidal field.

Orphula Stål. $f^{2}$. Foveolae of vertex wanting; prozona very much longer than metazona; lateral lobes of pronotum longitudinal, longer than or fully as long as deep; upper ulnar vein of tegmina, at least in $\delta$, apically strongly arched, joining the lower ulnar vein not far beyond the end of the basodiscoidal field.

$g^{1}$. Lateral lobes of pronotum slightly tumid in descending by the obliquity of the upper portion; lateral carinae divergent on metazona; discoidal field of wings of $\delta$ distinctly narrowing apically.

Clinocephalus Morse.

$g^{2}$. Lateral lobes of pronotum plane, vertical; lateral carinae parallel on metazona as on prozona; dis- 
coidal field of wings in $\delta$ hardly narrowing apically.

Dichromorpha Morse.

$e^{2}$. Antennae long, about or more than half as long again as head and pronotum together; fastigium of vertex with a median carina; scapular area of tegmina distinctly dilated in both sexes, but especially in the male. . Chloealtis Harris.

$A^{2}$. Foveolae of the vertex always present, visible from above, their plane forming an obtuse angle with the plane of the fastigium; face usually more nearly vertical than in the alternate category.

$b^{1}$. Tegmina with well-formed intercalary vein.

$c^{1}$. Inner apical spurs of hind tibiae subequal in length; apical portion of scapular field of $\delta$ tegmina (and sometimes the adjoining parts) so dilated that the broadest part of the tegmina lies beyond the middle (Stenobothri.)

$d^{1}$. Antennae filiform.

$e^{1}$. Face considerably oblique, straight or little rounded; foveolae of vertex slender; lateral lobes of pronotum longer than, or fully as long as deep; interspace between the mesosternal lobes narrower than the lobes themselves.

$f^{1}$. Fastigium with a distinct median carina; lateral carinae of pronotum subparallel, the disk fully two and a half times as long as posterior breadth; scapular area of $\delta$ tegmina abruptly and greatly widened beyond the middle.

Napaia McNeill.

$f^{2}$. Fastigium with no median carina but only a colored line; lateral carinae of pronotum distinctly though not greatly sinuate, the disk thereby clepsydral and hardly twice as long as posterior breadth; scapular area of $\delta$ tegmina gradually and less conspicuously widened beyond the middle.

Stenobothrus Fischer.

$e^{2}$. Face little oblique, strongly rounded; foveolae moderately broad, never more than twice as long as broad; lateral lobes of pronotum deeper than long; interspace between mesosternal lobes as broad as the lobes themselves.

$f^{1}$. Hind margin of pronotum more angulate than front margin; posterior margin of lateral lobes straight; tegmina and wings fully developed.

Platybothrus n. g. (Note 7.) $f^{2}$. Fore and hind margins of pronotum equally (and 
slightly) angulate; posterior margin of lateral lobes sinuate; tegmina abbreviate and wings aborted.

Bruneria McNeill (Note 8.)

$d^{2}$. Antennae apically clavate. . . Gomphocerus Thunberg. $c^{2}$. Inner apical spurs of hind tibiae very unequal in length, the inferior twice or nearly twice as long as the superior; apical portion of scapular field of $\delta$ tegmina but little dilated, so that the broadest part of the tegmina lies at the middle (Scyllinae).

$d^{1}$. Median carina of pronotum as distinct on prozona as on metazona, cut only by the principal sulcus.

$e^{1}$. Fastigium of the vertex rounded, without or with suppressed lateral costulation; hind tibiae with $14-16$ spines on the outer margin.

Boopedon Thomas.

$e^{2}$. Fastigium of the vertex hollowed, with distinct lateral costulation; hind tibiae with 9-1 2 spines on outer margin.

$f^{1}$. Eyes elongate, nearly twice as long as broad; frontal costa prominent, advanced in front of eyes by more than half the shorter diameter of the latter; tegmina with definite pantherine pattern. Plectrotettix McNeill (Note 9.) $f^{2}$. Eyes suborbicular, much less than half as high again as broad; frontal costa not prominent, advanced in front of eyes by less than half the shorter diameter of latter; tegmina irregularly and obscurely flecked.

$g^{1}$. Pronotum subtruncate posteriorly, the prozona much longer than the metazona; tegmina and wings abbreviate. . Eupnigodes McNeill (Note io). $g^{2}$. Pronotum more or less angulate posteriorly, the prozona and metazona equal or subequal; tegmina and wings fully developed.

$h^{1}$. Pronotum constricted in the middle, the prozona slightly the shorter; lateral carinae precurrent, very divergent in front and behind.

Stirapleura Scudder (Note II). $h^{2}$. Pronotum not constricted in the middle, the prozona slightly the longer; lateral carinae obsolete on the prozona, moderately divergent behind.

Ageneotettix McNeill (Note I2). $d^{2}$. Median carina subobsolete posteriorly on the prozona, cut by its sulci, as well as by the principal sulcus. Aulocara Scudder (Note I3). 
$b^{2}$. Tegmina with distinct intercalary vein (Epacromiae).

$c^{1}$. Intercalary vein slender, intermediate between radial and ulnar veins ; mediastinal vein of $\delta$ short, not reaching middle of tegmina, the scapular area beyond it dilated, scalariform-veined; median carina of pronotum obsolescent.

Ligurotettix McNeill. $c^{2}$. Intercalary vein stout, nearer the ulnar than the radial vein; mediastinal vein of $\delta$ reaching well beyond the middle of the tegmina, the scapular area beyond it insignificant; median carina of pronotum distinct, sharp.

Mecostethus Fieber.

Note I. Rhadinotatum. I correct the spelling of McNeill's name, the initial letter of the Greek word from which he derives it having a rough breathing.

Note 2. Tryxalis. I have given in Psyche, viii, I68, my reason for supporting McNeill in his use of this generic term, instead of Metaleptea Brunner.

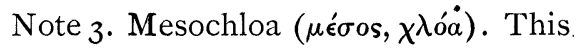
new generic name is proposed for Eritettix abortivus Brun., readily separable from Eritettix by the characters given in the table, and, indeed, nearer to the following genus.

Note 4. Macneillia. This name is suggested to replace Pedeticum $\mathrm{McNeill}$, preoccupied by Pedeticus Laporte in Hemiptera. It is founded on Chrysochraon obscurus Scudd.

Note 5. Opeia. This name is erroneously spelled Oreina in McNeill's key; see his note in Psyche, viii, 7 r.

Note 6. Phlibostroma. The genus named Beta by Brunner in his Système is the same as this, which has priority. See my note in Can. ent., xxix, 76.

Note 7. Platybothrus ( $\pi \lambda \alpha \tau \dot{v} s, \beta o ́ \theta_{\rho \circ s}$ ).
This new genus is founded upon Stenobothrus brunneus Thom.

Note 8. Bruneria. Given as Brunneria (preoccupied) in McNeill's Revision, but corrected by him in Psyche, viii, $7 \mathrm{I}$.

Note 9. Plectrotettix. Given Plectrophorus by McNeill in his Revision, but being preoccupied this name was changed by him to the present form; see Psyche, viii, 7 I.

Note ro. Eupnigodes. For a similar reason and in the same place, this name was substituted for Pnigodes of the Revision.

Note I I. Stirapleura. As I have pointed out in Can. ent., xxix, 76, Pseudostauronotus Brunner is identical with this and of more recent date.

Note I 2. Ageneotettix. In Psyche viii, 7 $\mathrm{I}, \mathrm{McNeill}$ substituted this name for Eremnus of his Revision, preoccupied. See also my remarks in Can. ent., xxix, 75, and Psyche viii, $7 \mathrm{I}$.

Note I3. Aulocara. This is the later Oedocara of Scudder and Coloradella of Brunner. See my notes in the places last cited. 


\section{A NEW VOLUME OF PSTCHE}

began in January, 1897 , and will continue through three years. The subscription price (payable in advance) is $\$ 5.00$ per volume, or $\$ 2.00$ per year, postpaid. Numbers are issued on the first day of each month. Libraries and individuals generally ordering through subscription agencies (which only take annual subscriptions) will please notice that it is cheaper to subscribe for the entire volume at once directly of us. - Any early volume can be had for $\$ 5.00$, unbound. Address Psyche, Cambridge, Mass.

Vols. I-7, Complete, Unbound - - - = - - \$33.00.

Vols. 1-7, and Subscription to Volume 8 - = - - \$37.00.

Vol. 7 contains over 500 pp. and 10 plates, besides other illustrations.

Guide to the Genera and Classification of the Orthoptera of North America north of Mexico. By Samuel H. Scudder. $90 \mathrm{pp} .8^{\circ}$.

Contains keys for the determination of the higher groups as well as the (nearly 200) genera of our Orthoptera, with full bibliographical aids to further study. Sent by mail on receipt of price $(\$ 1.00)$.

E. W. Wheeler, 30 Boylston Street, Cambridge, Mass.

A. SMITH \& SONS, 269 PEARL STREET, New York.

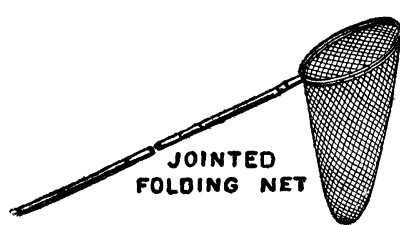
GOODS FOR ENTOMOLOGISTS,

Klaeger and Carlsbad Insect Pins, Setting

Boards, Folding Nets, Locality and Special Labels, Forceps, Sheet Cork, Esc. Other articles are being added, Send for List.

\section{The Butterflies of the Eastern United States and Canada.}

With special reference to New England. By Samuel H. Scudder.

Illustrated with 96 plates of Butterflies, Caterpillars, Chrysalids, etc. (of which $4 \mathrm{I}$ are colored) which include about 2,000 Figures besides Maps and portraits. 1958 Pages of Text.

Vol. I. Introduction; Nymphalidae.

Vol. 2. Remaining Families of Butterflies.

Vol. 3. Appendix, Plates and Index.

The set, 3 vols., royal 8 vo. half levant, $\$ 75.00$ net.

HOUGHTON, MiffliN \& CO., 4 Park St., Boston, Mass. 

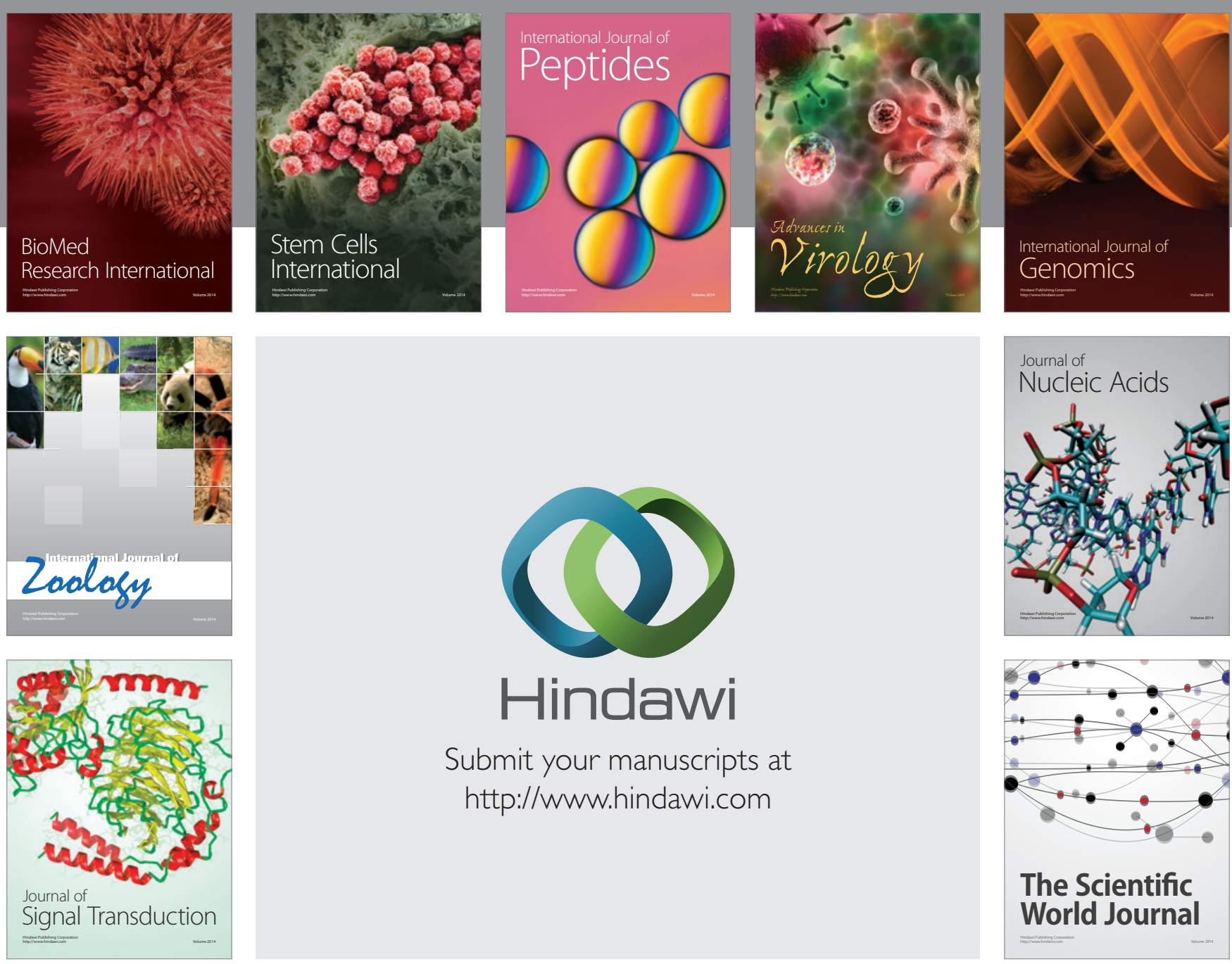

Submit your manuscripts at

http://www.hindawi.com
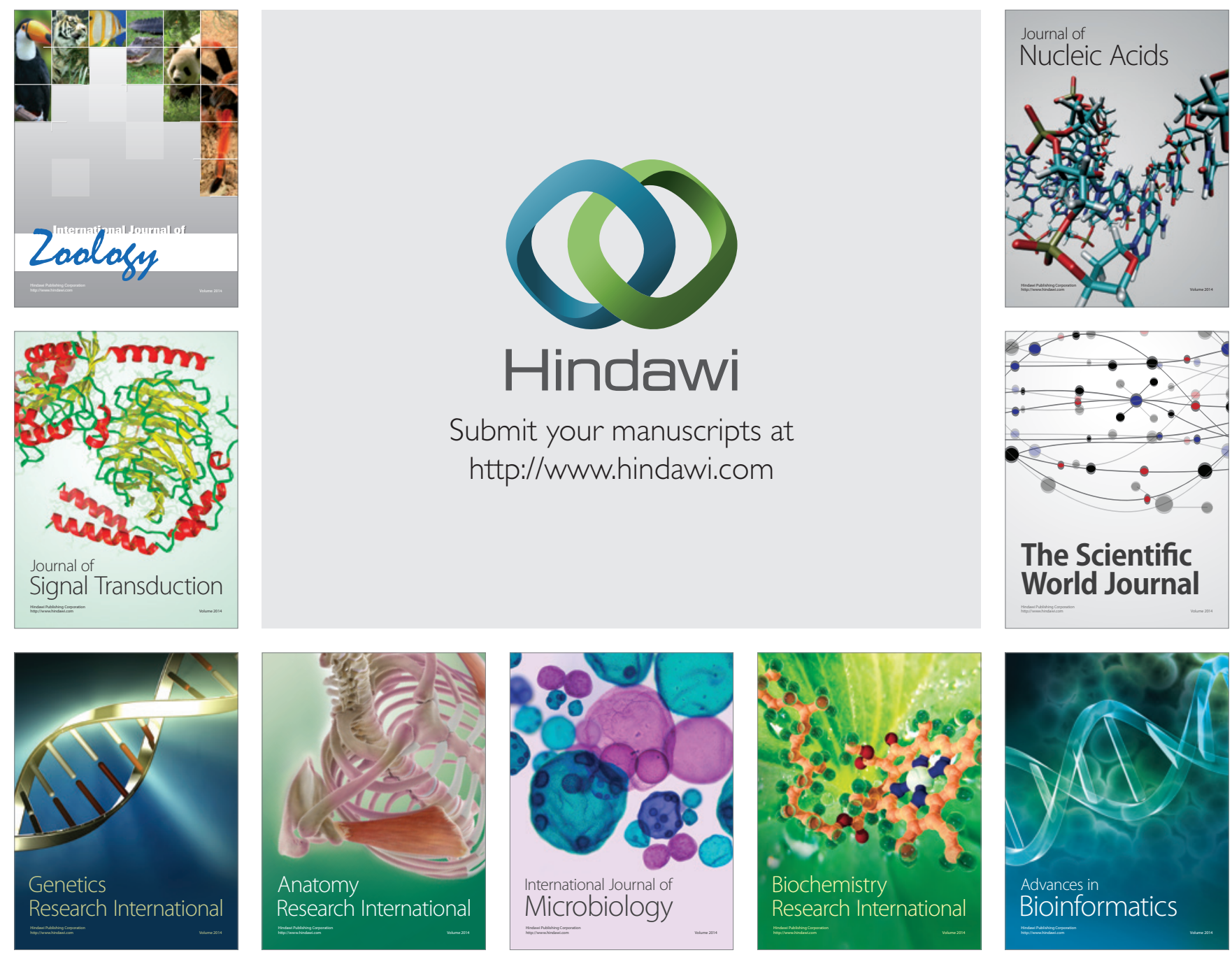

The Scientific World Journal
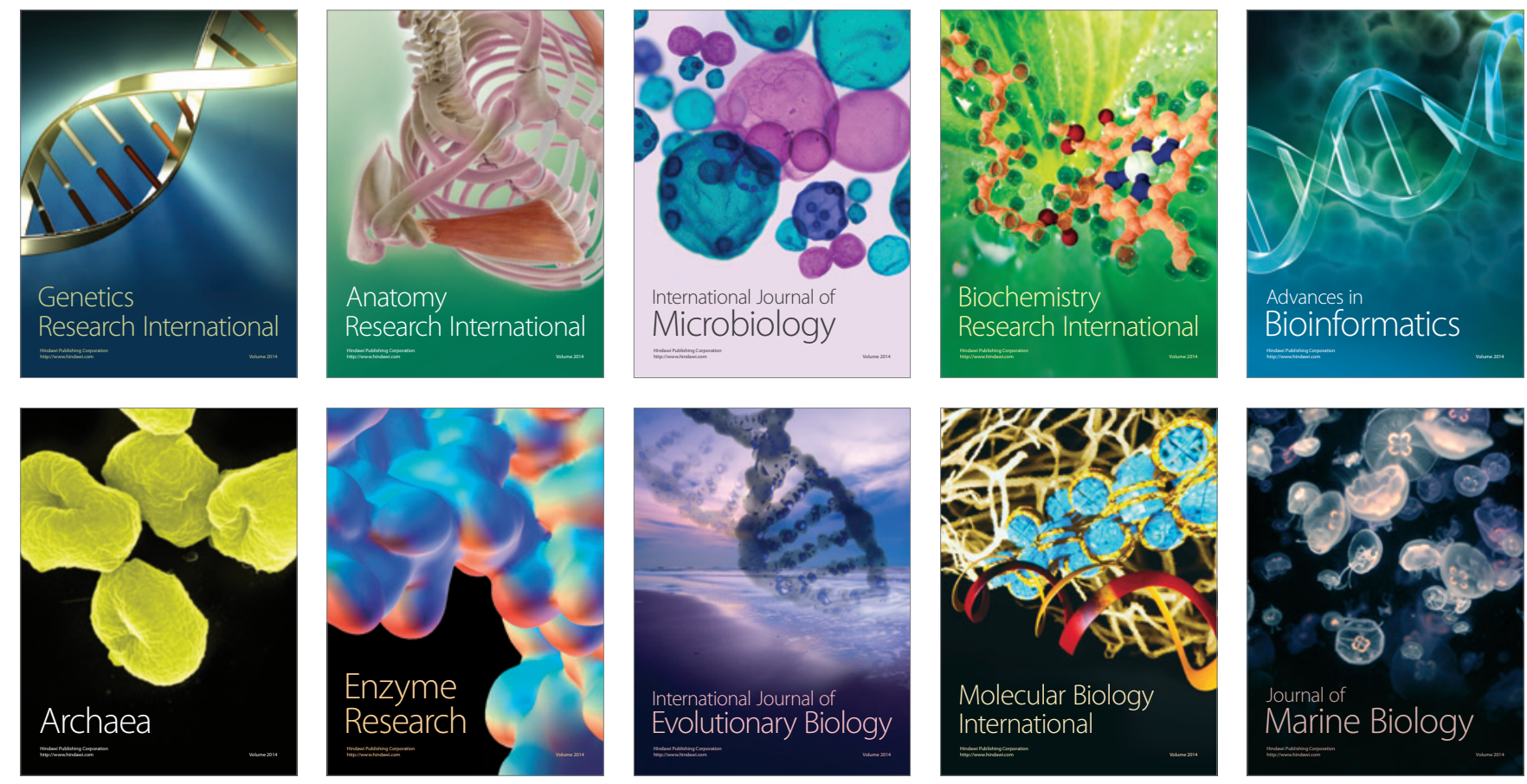